\title{
Reflexões sobre a viabilização de survey como abordagem metodológica para pesquisa em controle gerencial
}

\author{
Fabio Frezatti \\ https://orcid.org/0000-0002-5927-022X | E-mail: frezatti@usp.br \\ Franciele Beck \\ https://orcid.org/0000-0001-7390-5933 | E-mail: fbeck@furb.br \\ Daniel Magalhães Mucci \\ https://orcid.org/0000-0002-0658-1470 | E-mail:danielmmucci@usp.br \\ Daiani Schlup \\ https://orcid.org/0000-0002-8052-6250｜Ｅ-mail: daianischlup@gmail.com
}

\section{Resumo}

Objetivo: Discutir aspectos metodológicos da abordagem survey na área de controle gerencial, em situações em que o desafio de estruturação do conjunto de dados seja uma realidade, relacionamento com o respondente, gerenciamento da coleta de dados, lógica de comunidade de pesquisa e a confiabilidade das informações. A motivação decorre da necessidade de desenvolvimento e aperfeiçoamento dessa abordagem, em face das demandas enfrentadas no processo de investigação pela ausência de dados.

Método: Como base para a discussão dos aspectos metodológicos, o estudo baseou-se no action research, utilizando um survey conduzido sobre o processo de planejamento e controle em empresas familiares como pano de fundo.

Resultados: Chamam a atenção para: (i) a importância da definição da população-alvo e amostra, a escolha dos critérios de agregação e os meios de acesso às empresas; (ii) a operacionalização da coleta de dados, em que se observou a necessidade de comunicação e sensibilização do respondente;e (iii) a importância da lógica de comunidade de pesquisa, associada ao estabelecimento e cumprimento do contrato de pesquisa. Contribuições: $\mathrm{O}$ estudo discute reflexões sobre a viabilização da abordagem survey e propõe soluções para os problemas vivenciados. Quanto ao impacto, pesquisas que não são desenvolvidas por ausência de respostas para a sua atividade de campo poderiam ser apresentadas e discutidas, proporcionando incremento de conhecimento na comunidade. Os autores esperam que os conhecimentos apresentados tenham utilidade para pesquisas de situações assemelhadas.

Palavras-chave: Método Survey;Abordagem Metodológica; Controle Gerencial. 


\section{Introdução}

O ambiente de pesquisa da área de ciências sociais aplicadas se desenvolveu ao longo do tempo a partir do paradigma das hard sciences. O ponto de partida foi natural como acomodação de área dentro do universo científico, mas atrelou durante muito tempo o avanço do conhecimento a uma lógica que não atende integralmente à demanda dos pesquisadores da área de sociais aplicadas. Saunders, Lewis e Thornhill (2019) ponderam que a área de pesquisa em negócios absorveu perspectivas filosóficas e metodológicas de diversas fontes (como ciências naturais, sociais, aplicadas e humanas), as quais definem a multiplicidade de perspectivas utilizadas pela área de negócios atualmente.

Muito embora universalmente os pesquisadores exijam o rigor científico das pesquisas (Merchant, 2012), a tradução do que isso significa demanda a visão de contexto para o qual a pesquisa tenha utilidade. Dessa maneira, algumas soluções metodológicas, consideradas inaceitáveis em algumas áreas, são razoáveis em outras. Por exemplo, enquanto algumas áreas do conhecimento, como engenharia, medicina ou até finanças, seguem critérios 'rígidos' para a amostragem representativa da população da pesquisa, vislumbrando a generalização dos resultados, em outras a falta de informação precisa sobre a população ou sobre aspectos que auxiliariam na delimitação da amostragem traz a necessidade de um olhar de adaptação e flexibilização desse processo. Flexibilização não implica abrir mão do rigor científico, mas customizar o rigor dentro da realidade e possibilidade de execução. A própria lógica de geração de conhecimento muda de dimensão, não dependendo unicamente do olhar quantitativo (Ketokivi \& Choi, 2014).

Embora o problema de pesquisa a ser tratado possa ter utilidade para a área de ciências sociais aplicadas como um todo, o trabalho de campo deste estudo foi desenvolvido na área de Controle Gerencial. Em particular, autores seminais na área de controle gerencial têm questionado esse contexto (Shields, 2015; Merchant, 2010). Segundo Merchant (2010, p. 119), "Algumas tradições de pesquisa importantes (por exemplo, análise histórica, pesquisa de campo, pesquisa survey) estão sendo eliminadas da área de contabilidade." $E$, desse modo, pesquisas relevantes que poderiam trazer impacto no ambiente deixam de ser feitas ou comunicadas até que sobrevivam aos desafios críticos impostos à pesquisa (Shields, 2015). Enquanto a literatura de metodologia sugere vantagens e limitações relacionadas a cada método especificamente (Smith, 2019), os gatekeepers (editores de revistas, pareceristas) têm sido mais céticos e críticos em relação a alguns métodos como é o caso do desenho e execução de surveys (Speklé\&Widener, 2018).Van der Stede, Young e Chen (2006) pontuam que as críticas não são ao método survey em si, mas a como ele se desdobra na prática.

$\mathrm{Na}$ literatura existem estudos que abordam o uso de survey em pesquisas da área contábil e de administração com diversos pontos de vista, por exemplo, Mac Lennan e Avrichir (2013) destacam que a replicação de pesquisas survey é algo interessante para o aumento da confiabilidade dos levantamentos realizados em estudos anteriores, comenta-se inclusive sobre a disponibilização dessas bases de dados. Outros autores como Freitas, Oliveira, Saccol e Moscarola (2000) e Carneiro e Dib (2011) tecem seus trabalhos pontuando algumas das vantagens e desvantagens da utilização de survey em pesquisas. Destacase que muitos estudos estão sendo desenvolvidos em ambientes on-line e que erros de amostragem, não resposta, e até questões éticas devem ser mitigados sem que isso custe o sucesso da pesquisa (Carneiro \& Dib, 2011). O que se coloca é que, em alguns temas de pesquisa, ou se utiliza esse método para captar os dados ou a pesquisa não é desenvolvida, dadas as características dos dados demandados.

Ao se pensar nas dificuldades da execução de um survey, uma primeira reação seria falar de escalas, tamanho de amostras, estruturação de população, aleatoriedade e mesmo o próprio conceito de generalização (Van der Stede, Young, \& Chen, 2006; Speklé\&Widener, 2018;Smith, 2019). No entanto, as dificuldades começam muito antes como, por exemplo, o acesso à população-alvo e a disposição de executivos com tempo limitado para participarem de pesquisas (Van der Stede et al., 2006; Saunders et al., 2019). Em outras palavras, para desenvolver a análise estatística é necessária a disponibilidade dos dados que, por sua vez, depende da estruturação da população e amostra, acesso e obtenção destes dados (Saunders et al., 2019). 
Muitos pesquisadores têm utilizado as mesmas bases de dados ao longo dos anos (Revista Melhores e Maiores, Valor 1000, Estadão, por exemplo) que, juntas, listam em torno de duas mil empresas. Se por um lado temos vários estudos e resultados sobre um mesmo conjunto de empresas, por outro grande parte das empresas brasileiras está no radar dos pesquisadores e suas particularidades não são percebidas nem tratadas, como é o caso das empresas familiares (Bressan, Schiehll, Procianoy, \& Castro, 2019). Como consequência, tanto a assertividade dos achados como as contribuições das pesquisas podem ter sua relevância limitada pelo fato de ser inevitável que a perspectiva da abordagem metodológica se afastedas abordagens tradicionais.

A evolução das organizações, no ambiente em que a palavra ruptura proporciona demandas para soluções de problemas em que os dados não estão disponíveis, provoca nos pesquisadores um dilema entre pesquisar algo em que a dificuldade de obter e tratar dados se contrapõe a continuar pesquisando problemas já relativamente resolvidos (Shields, 2015; Lindsay, 2018; Merchant, 2012). Em outras palavras, também na pesquisa, a inovação de ruptura ou incremental se contrapõe à manutenção do status quo (Merchant, 2012; 2010; Ribeiro, 2014). Nesse sentido, identificar propostas de soluções para o acesso, a coleta e o tratamento de dados é fundamental para o desenvolvimento do campo de conhecimento (Speklé\&Widener, 2018; Hiebl\& Richter, 2018). Para isso, a "qualidade" da informação é essencial, o que pode ficar difícil de perceber caso não seja discutida e planejada antecipadamente.

Dessa forma, se por um lado a realização de survey permite a coleta de dados primários e, portanto, útil para o conhecimento das empresas brasileiras, por outro a própria falta de informações para o mapeamento e estruturação da população desejada torna-se um entrave ao método. Assim, o problema de pesquisa consiste em dispor de dados adequados para o desenvolvimento de survey se, deste modo, permitir o avanço nas discussões de problemáticas pouco desenvolvidas ou mesmo inexploradas no ambiente empresarial brasileiro, tendo por questão de pesquisa: como tratar os dilemas para viabilização da pesquisa survey? Esta questão será subsidiada por cinco questões que operacionalizam a análise e propostas.

Deste modo, este artigo tem por objetivo discutir aspectos metodológicos da abordagem survey na área de controle gerencial, considerando a estruturação do conjunto de dados, o relacionamento com o respondente, o gerenciamento da coleta de dados, o senso de comunidade de pesquisa e a confiabilidade das informações.A pesquisa justifica-se devido à demanda de um olhar interno, no que tange às organizações, ao tipo de informação requerida, não disponível, em que as proxies não trazem conforto aos pesquisadores e ao relacionamento pretensamente de longo prazo e retributivo.

Em termos de inovação, como resultado das reflexões, identificações de propostas para os problemas, destaca-se a utilização do action research, no desenvolvimento da análise dos elementos metodológicos valendo-se como uma abordagem de pesquisa em que soluções contextuais foram identificadas e agregadas ao processo de pesquisa. No entender de Tripp (2005), além de ser utilizada como suporte para informação e decisão,tem potencial para melhorar uma prática, que é o que pretendemos fazer nesta pesquisa. Complementarmente, permite examinar as proposições teóricas correntes e para se buscar novas possibilidades teóricas para explicação da realidade (Lodi, Thiollent, \& Sauerbronn, 2017). Isso pode ser obtido porque a abordagem action research pode ser utilizada para compreender problemas, implementar e avaliar soluções (Coughlan\&Coghlan, 2002) sobre a condução de surveys. Na presente pesquisa, o pano de fundo, o campo considerado por um grupo da área de contabilidade gerencial focou o processo de planejamento e controle em empresas familiares. O impacto do estudo decorre da identificação de alternativas de desenvolvimento de pesquisas apoiando novos estudos sobre temas relevantes que se utilizem do levantamento (surveys).

De forma mais específica, a contribuição da pesquisa consiste em proporcionar estrutura conceitual para que futuras pesquisas de levantamento (survey) possam:(i) evidenciar a estruturação da base de dados populacional que permita o desenvolvimento de pesquisas e suas contribuições e utilizações legitimadas na comunidade; (ii) refletir e discutir os desafios envolvidos no design e operacionalização da coleta de dados; (iii) chamar a atenção para a necessidade da criação de uma comunidade de pesquisa e assim viabilizar um ambiente sustentável para a continuidade de pesquisas sob essa perspectiva. 
O trabalho está organizado em cinco seções, considerando esta introdução. Na seção dois apresentaremos as reflexões sobre a abordagem survey em pesquisas em controle gerencial com base em estudos nacionais e internacionais, seguida da seção três em que justificamos a utilização do action research como abordagem metodológica. Na seção quatro realizamos a análise e discussão de questões orientativas, avaliando as principais reflexões da literatura e as intervenções que foram realizadas no contexto empírico específico de condução do survey com empresas familiares brasileiras. Por fim, na seção cinco, abordamos os principais achados do estudo, bem como as reflexões e soluções para futuras pesquisas.

\section{Reflexões sobre survey sem controle gerencial}

Pesquisas usando a estratégia de survey são amplamente utilizadas nas áreas de ciências sociais aplicadas devido à sua capacidade de fornecer informações relevantes, não disponíveis (percepção, sentimento, opinião, fato, etc.) efetivamente de um grupo-alvo questionado, de acordo com um determinado objetivo de pesquisa (Dillman, Smyth, \& Christian, 2014; Saunders et al., 2019). Na maioria dos casos, pesquisas survey são utilizadas para testar teorias ou aperfeiçoá-las, coletando um conjunto de dados em potencial e realizando análises,resultando na ampliação de conhecimento acadêmico e empresarial (Bisbe, Batista-Foguet, \&Chenhall, 2007; Speklé\&Widener, 2018; 2020). Para determinados problemas de pesquisa, utilizar dados disponíveis como proxies pode ser possível,mas isso nem sempre ocorre e a informação primária pode ser o diferencial qualitativo que contribui para a confiabilidade do aumento do conhecimento (Saunders et al., 2019).

A questão guarda-chuva que permite refletir sobre os elementos que proporcionam a discussão do tema é como tratar os dilemas para viabilização da pesquisa survey? A rigor, ela estimula a reflexão e identificação das questões sobre a operacionalização da pesquisa. As questões que são desdobradas desse guarda-chuva são apresentadas na Figura 1, e serão exploradas na sequência.

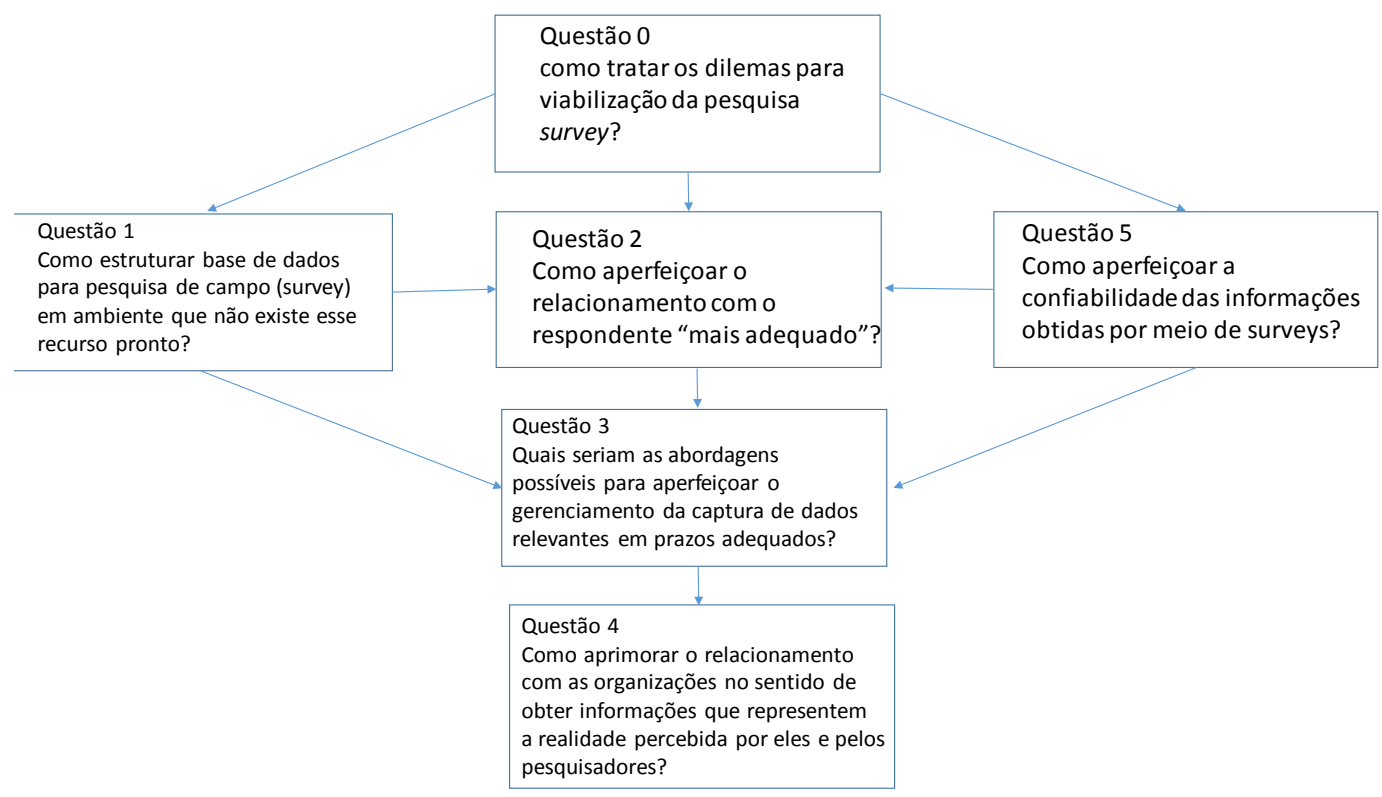

Figura 1. Síntese das questões tratadas. 
Apesar do avanço tecnológico,no cenário atual de pesquisas agravam ainda mais as dificuldades em realizar pesquisas survey, e as baixas taxas de respostaacabam sendo arealidade. Embora pesquisas anteriores tenham tentado fornecer insights de como solucionar as dificuldades encontradas durante a realização de survey, ainda existem algumas questões a serem estudadas, principalmente quando o foco é colocado no controle gerencial de empresas familiares. Quando se realiza uma pesquisa survey busca-se, além das respostas do perfil do gestor, captar a essência da organização e dos processos em que o indivíduo está inserido, e isso torna-se ainda mais difícil quando as organizações investigadas, por exemplo, são empresas familiares, sem uma base de dados prévia para acesso.Entendendo a necessidade do uso do survey em função do tipo de dados demandados, surgem problemas com a amostragem e o papel do survey em função do objetivo (Van der Stede et al., 2006), sendo complexa a dimensão de abrangência da população-alvo. Como consequência, estabelecemos questões a serem tratadas nesta pesquisa: Questão 1:Como estruturar base de dados para pesquisa de campo (survey) em ambiente em que não existe esse recurso pronto?

Além do aspecto relacionado à população e à amostra, outra dificuldade é a de definir e encontrar o respondente adequado na implementação survey. Isso é algo que incomoda os pesquisadores, o nível de controle é discutível e o tipo de concessão que possa não afetar o produto final da pesquisa está na mente dos pesquisadores. Hiebl e Richter (2018) discutem a questão do nível hierárquico e a taxa de resposta é o outro lado da equação (Hartmann \&Slapničar, 2012). Em decorrência da importância do tema, é especificada a Questão 2: Como aperfeiçoar o relacionamento com o respondente "mais adequado"?

Vale destacar que vários meios podem ser empregados durante a coleta de dados de uma pesquisa survey, tais como correio, telefone, $e$-mail e internet, sendo que cada plataforma possui vantagens e desvantagens (Smith, 2019; Saunders et al., 2019). Em comparação aos modelos tradicionais de pesquisas, os levantamentos feitos de forma on-line apresentam diversas vantagens, dentre elas, um menor tempo de envio do questionário, menor custo de entrega, mais opções de design e menor tempo para o recebimento das respostas. No entanto, as pesquisas on-line também enfrentam desafios específicos, como a perda de participantes durante o processo e a baixa taxa de resposta que podem levar a resultados tendenciosos (Couper, 2000; Fricker\&Schonlau, 2002; Hiebl\& Richter, 2018).

Visto que a taxa de resposta em pesquisas on-line tem sido uma grande preocupação para os pesquisadores, Fan e Yan (2010) e Keusch (2015) desenvolveram um modelo conceitual por meio de revisões sistemáticas para encontrar os fatores que influenciam a taxa de resposta tanto no estágio de desenvolvimento da pesquisa quanto na entrega dos questionários, conclusão da pesquisa e feedback. Os autores verificaram que o sucesso da pesquisa é significativamente influenciado por fatores como quantidade de tópicos, tempo necessário para responder o questionário, formatação e design do instrumento, facilidade em acessar o link do questionário em diversos navegadores e aparelhos.

A captura de dados tem, além do aspecto quantitativo, do número de respostas disponibilizado, o lado qualitativo, que nem sempre caminham lado a lado. Alguns desafios são apresentados na literatura, tais como Cycyota e Harrison (2006), que indicam que uma série de providências como consentimento prévio, acompanhamento, lembretes e personalização não foram consideradas eficazes para melhorar a taxa de resposta em pesquisas com executivos da alta administração. Por outro lado, Hiebl e Richter (2018) tratam a questão do contato prévio com o potencial respondente, uso de amostra não aleatória e foco em gestores de nível hierárquico mais baixo. 
Sabe-se ainda que survey é uma das abordagens quantitativas mais frequentemente utilizadas na pesquisa em contabilidade gerencial, sendo o número de respostas utilizáveis e as altas taxas de respostas características importantes para a utilização deste método (Hiebl\& Richter, 2018). No entanto, ao realizarem um estudo investigando 140 artigos publicados em revistas de alto impacto, Hiebl e Richter (2018) evidenciaram que, nos últimos anos, as taxas de resposta nas pesquisas em contabilidade gerencial sofreram uma tendência de queda. Também descobriram que o tamanho da população da pesquisa, a região onde as pesquisas são realizadas, a escala das pesquisas, o nível hierárquico dos entrevistados, os tópicos examinados, as técnicas de amostragem aleatória e o estabelecimento de contato com a população da pesquisa antes de enviar questionários são todos fatores que estão significativamente associados à taxa de resposta e sucesso da pesquisa. Dessa maneira, a Questão 3 foi estruturada: Quais seriam as abordagens possíveis para aperfeiçoar o gerenciamento da captura de dados relevantes em prazos adequados?

Uma pesquisa não é algo frio, neutro e sem qualquer impacto na sociedade, mas algo que afeta a vida dos agentes e eles reagem aos estímulos. Uma possível forma de olhar para isso é a questão do impacto social que ela traz (ou deveria trazer) para a comunidade (Nicolai \&Seidl, 2010). Proporcionar condições para os respondentes entenderem faz parte das atividades dos pesquisadores. Sem aproximação do ambiente acadêmico com o campo, tanto as pesquisas deixarão de olhar para elementos relevantes como a sociedade deixará de entendê-los (Shields, 2015; Lindsay, 2018; Merchant, 2012), o que motiva a Questão 4: Como aprimorar o relacionamento com as organizações no sentido de obter informações que representem a realidade percebida por eles e pelos pesquisadores?

Confiabilidade das respostas é outro aspecto fundamental (Van der Stede et al., 2006) e de difícil solução. Pode ser vista por vários ângulos, quais sejam: o erro de não amostragem, o erro de não resposta, $o$ erro de resposta, o social desirability bias, entre outros indicativos (Podsakoff, MacKenzie, Lee, \&Podsakoff, 2003; Van der Stede et al., 2006; Speklé e Widener, 2018). Certamente muitos pesquisadores que utilizam o survey como abordagem metodológica refletem sobre em que medida os erros e vieses inviabilizam os seus achados e conclusões. Essa reflexão é crucial e perpassa de forma geral todas as outras questões orientativas. Esses aspectos demandam a construção da Questão 5. Como aperfeiçoar a confiabilidade das informações obtidas por meio de surveys?

É importante destacar que essas questões são discutidas por livros e artigos com foco metodológico (por exemplo, Van der Stede et al., 2006; Saunders et al., 2019; Smith, 2019). A intenção deste artigo,portanto,não é suprir o conhecimento básico relacionado ao desenho e à implementação de surveys, mas contribuir por meio de propostas identificadas, customizadas e empregadas em uma pesquisa survey sobre o processo de planejamento de empresas familiares, discutir questões críticas vivenciadas na condução da pesquisa e cujas preocupações sejam compartilhadas por outros pesquisadores da área de controle gerencial (Van der Stede et al., 2006; Speklé\&Widener, 2018; Hiebl\& Richter, 2018).

\section{Desenho da pesquisa}

A pesquisa foi conduzida a partir da interação com o campo. Utilizou-se a abordagem indutiva, com inspiração na pesquisa-ação (na sua variante action research), (Coughlan \& Coghlan, 2002; Thiollent, 2009), que conta com forte interação com o campo, principalmente no que se refere a tratar temas emergentes em que o conhecimento do contexto e do campo podem trazer contribuições relevantes. 


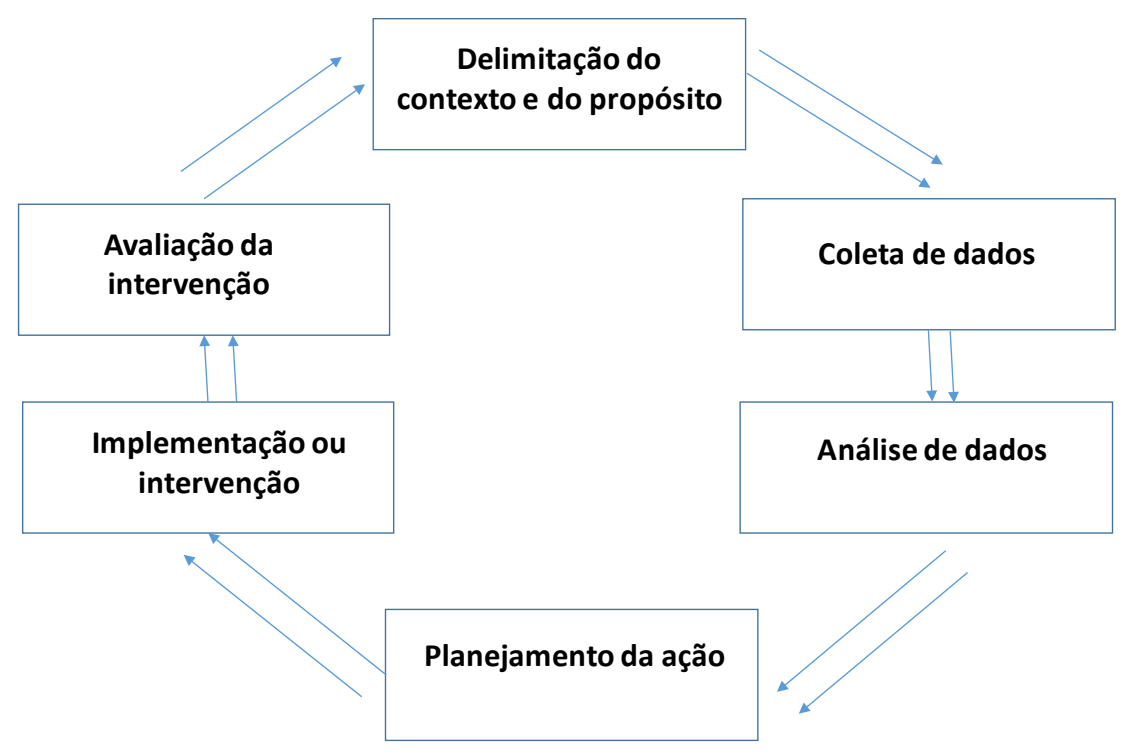

Figura2.Dinâmica do modelo Coughlan \& Coghlan (2002).

Fonte: adaptada de Coughlan, P., \& Coghlan, D. (2002). Action research for operations management. International Journa lof Operations \& Production Management, 22(2), pp. 220-240.

A Figura 2 indica a dinâmica do modelo de Coughlane Coghlan (2002), que pressupõe as seguintes etapas:primeiramente a delimitação do contexto e do propósito que, no caso deste estudo, consiste na prática de uma pesquisa survey nas empresas familiares. A referida pesquisa teve como foco tratar o processo de planejamento em empresas familiares brasileiras privadas de diversos portes. Devido à temática, delimitou-se como respondentes-alvo membros da família, gestores da alta administração preferencialmente aqueles vinculados à área de administração, controladoria e finanças.

Todas as etapas e decisões em relação ao design e aplicação do survey sob investigação serviram de base para a presente pesquisa. A coleta de dados refere-se às evidências e notas tomadas a partir das reuniões periódicas de discussão realizadas ao longo da aplicação do survey e acompanhamento das respostas. A análise de dados envolve a troca de informações entre pesquisadores e empresas no sentido de entender, por exemplo, o que levou um respondente a participar da pesquisa e qual a sua percepção sobre a interação entre academia e empresa. O planejamento da ação abrange as intervenções que suscitaram utilização de abordagens adicionais àquelas inicialmente planejadas para o desenvolvimento do survey. Quanto à implementação ou intervenção, cabe destacar, por exemplo,a delimitação do respondente-alvo para a pesquisa, a utilização de vídeos para o convite de potenciais respondentes, os formatos de convites e lembretes utilizados na pesquisa ( follow up), identificação do respondente, entre outras estratégias adotadas.

Em relação à avaliação da intervenção ao processo de coleta de dados, os pesquisadores discutiram periodicamente ao longo do processo de pesquisa os resultados parciais que as estratégias adotadas geraram em termos de número de respostas e confiabilidade das respostas obtidas por meio dos questionários, bem como uma reflexão em relação às perspectivas ética e técnica. As estratégias adotadas foram registradas e acompanhadas pelo grupo de pesquisadores em termos de reflexos nos resultados da coleta, conforme preconizado pela abordagem do action research (Coughlan\&Coghlan, 2002; Thiollent, 2009; Kemmis, McTaggart,\& Nixon, 2014).

Neste artigo, as etapas do action research foram aplicadas nas reflexões das cinco questões direcionadoras para a operacionalização da pesquisa. Em cada uma delas foram propostas discussões sobre (i) o que a literatura diz e o gap para a área, como ela se materializa e quais as limitações; e (ii) identificação e discussão de contribuição a partir das evidências empíricas. 


\section{Análise e discussão das questões orientativas}

Para a condução do presente estudo, cinco questões orientativas foram desenvolvidas e são discutidas na sequência.

Questão 1. Como estruturar base de dados para pesquisa de campo (survey) em ambiente em que não existe esse recurso pronto?

\section{O que a literatura diz e o gap para a área}

A não disponibilidade de conjunto de dados com caracterização da população-alvo de empresas com o perfil demandado pela pesquisa inviabiliza alguns tipos de estudo. Segundo dados do Instituto Brasileiro de Geografia e Estatística (IBGE -2019), a população de empresas de médio e grande porte (acima de 250 funcionários)é de mais de $85 \mathrm{mil}$. Grande parte dessas empresas não é acessada pela falta de informações como nome, região e contatos e, por isso, não são consideradas pelos estudos da área de controle gerencial.

A área de ciências sociais aplicadas sofre inúmeras críticas relacionadas ao pouco uso de técnicas de amostragem aleatória, a partir de uma população existente (Landers\&Behrend, 2015; Smith, 2019). O que se questiona é se a aleatoriedade atende ao seu propósito e pode contribuir para a qualidade da informação requerida nas diferentes problemáticas e interesses de pesquisa possíveis. No caso brasileiro, por exemplo, trocar o Itaú-Unibanco pelo Bradesco ou pelo Banco do Brasil ou pelo Santander a partir da aleatoriedade não faz sentido da perspectiva das suas diferenças em termos de estrutura, estratégias e comportamentos organizacionais, por exemplo.

Van der Stede et al. (2006), ao analisarem as técnicas de amostragem utilizadas por pesquisas em controle gerencial, identificaram a predominância de métodos não probabilísticos, particularmente amostras por conveniência (cerca de $70 \%$ dos estudos). A amostra por conveniência é uma estratégia comum para quando não se sabe qual a população do estudo,ou seja, quando da falta de bases de empresas com perfis e contatos dos potenciais respondentes.

Tomando por base a predominância de uso de amostra por conveniência em estudos na área de controle gerencial, Speklé e Widener (2018) sugerem uma diferença entre as limitações dessa abordagem para estudos descritivos e estudos que testam teorias. Segundo Speklé e Widener (2018), os estudos descritivos devem dar maior atenção à generalização dos resultados obtidos a partir da amostra para a população e nesse sentido demandam técnicas de amostragem probabilística (Van der Stede et al., 2006).

Já os estudos que testam teorias necessitam de uma amostra relevante sobre os sujeitos ou organizações aos quais a teoria se aplica e, por isso, as preocupações de delimitação da amostra recaem sobre o viés de abrangência/cobertura. O viés de abrangência está presente no estudo quando a lista inicial (sampling frame) não cobre a população-alvo (target population) (Speklé\&Widener, 2018).

\section{Identificação e discussão de contribuição a partir das evidências empíricas}

A construção da estrutura amostral pode ocorrer a partir da identificação de bases disponíveis nas quais seja possível agregar empresas com diferentes perfis demandados. Salienta-se que a estrutura amostral não precisa e talvez nem deva ser feita de forma totalmente aleatória ou simplesmente utilizando dados de bases existentes. Além do número de empresas que se deseja atingir, é necessário levar em consideração os tipos de empresas desejadas e selecionar de forma pertinente suas características, minimizando assim o erro de cobertura. Nesse sentido, torna-se importante que a estrutura amostral esteja alinhada com a população-alvo, ou seja, que apresente as características do perfil da população do grupo de empresas e/ou sujeitos a que a teoria discutida no estudo se aplicaria (Van der Stede et al., 2006; Speklé\&Widener, 2018). 
O projeto de pesquisa objeto de estudo definiu a estrutura amostral com base em empresas familiares estratificadas de acordo com o porte, segregando a amostra em quatro grupos sujeitos a diferentes graus de complexidades. Essa estratificação ocorreu pela expectativa dos autores para diferentes usos de práticas de controle gerencial e potencialmente em diferentes estágios de desenvolvimento organizacional e foi definida como critério básico para delimitação do perfil da população (Figura 3).

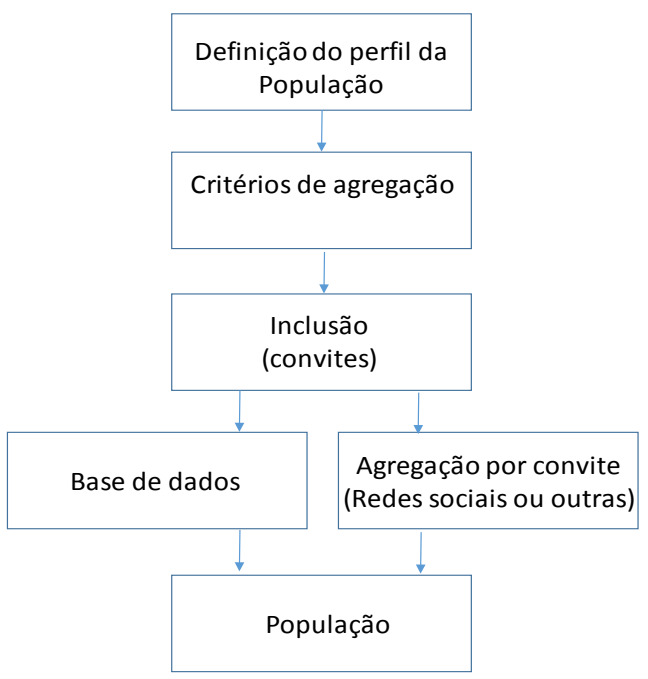

Figura 3. Estruturação da população do estudo.

A partir da definição desse critério de agregação à base de dados mediante a estratificação, procedeu-se ao convite às empresas, por meio dos seus gestores, para participarem do estudo (ver Figura 3). Por se tratar de uma composição heterogênea, cujos dados de empresas não estão em bases de dados disponíveis, os pesquisadores optaram por realizar os convites para inclusão das empresas de duas formas: primeiro com participantes de pesquisas anteriores, levando em consideração listas de empresas de pequeno, médio e grande porte, de bens duráveis e não duráveis (base de dados); segundo, por meio de convites a potenciais respondentes, que fossem da alta administração e que possuíssem perfis ativos na rede profissional LinkedIn ${ }^{\oplus}$, sempre se atentando às características da empresa que eram necessárias para responder o problema de pesquisa.

Uma vez definidas as características desejadas da estrutura amostral para definição da amostra, foi dado início ao processo de coleta de dados, cujos procedimentos são tratados nas próximas questões analisadas.

Questão 2. Como aperfeiçoar o relacionamento com o respondente "mais adequado"?

\section{O que a literatura diz e o gap para a área}

A definição do respondente mais adequado para pesquisas pode levar em consideração uma série de aspectos, dependendo do nível de análise do estudo. Se o nível de análise for organizacional, pode-se definir o perfil do respondente com base no seu nível hierárquico, tempo de empresa e participação no fenômeno a ser estudado (por exemplo, o processo orçamentário). Caso o nível seja o indivíduo, pode-se levar em consideração seu histórico de atuação, sua experiência profissional, suas características individuais. 
Alguns parâmetros são comumente utilizados em pesquisas de levantamento como o nível hierárquico do respondente, o tempo de atuação na empresa e no cargo e a área de atuação. Conforme Hiebl e Richter (2018) ponderam, quanto mais alto o nível hierárquico do gestor, maior dificuldade de obtenção de respostas. Quanto à área de atuação, pesquisas na área de controle gerencial, por exemplo, tendem a atrair maior interesse de executivos das áreas de finanças, no entanto há exemplos de estudos que foram desenvolvidos com gestores de outras áreas, cuja taxa de resposta pode ser considerada alta (e.g., Hartmann \&Slapničar, 2012). É importante atentar-se que: (i) o perfil do respondente mais adequado pode impactar a taxa de resposta do estudo; (ii) em muitas situações o "perfil-alvo" não é possível de se delimitar/aplicar;ou mesmo(iii) o acesso ao respondente nem sempre é viável. Portanto, o pesquisador deve definir qual o erro de resposta que para ele é aceitável do ponto de vista empírico e teórico.

$\mathrm{O}$ respondente adequado pode depender do conhecimento, experiência, nível hierárquico e mesmo função dentro da estrutura e o viés que possa ser tolerado. Podem ocorrer situações em que uma pesquisa pode demandar mais de um respondente por empresa para atender o escopo (e.g., Madison, Kellermanns,\&Munyon, 2017).

\section{Identificação e discussão de contribuição a partir das evidências empíricas}

Dispor de base de dados de empresas familiares é um dos exemplos de lacunadas pesquisas. Dispor de informações sobre diferentes respondentes é mais difícil ainda. A consequência dessa dificuldade é que na demanda por respostas qualitativas, com subjetividade, a influência sobre o entendimento e a utilização das respostas pode gerar conclusões distantes de uma realidade que poderia ser captada por diferentes respondentes.

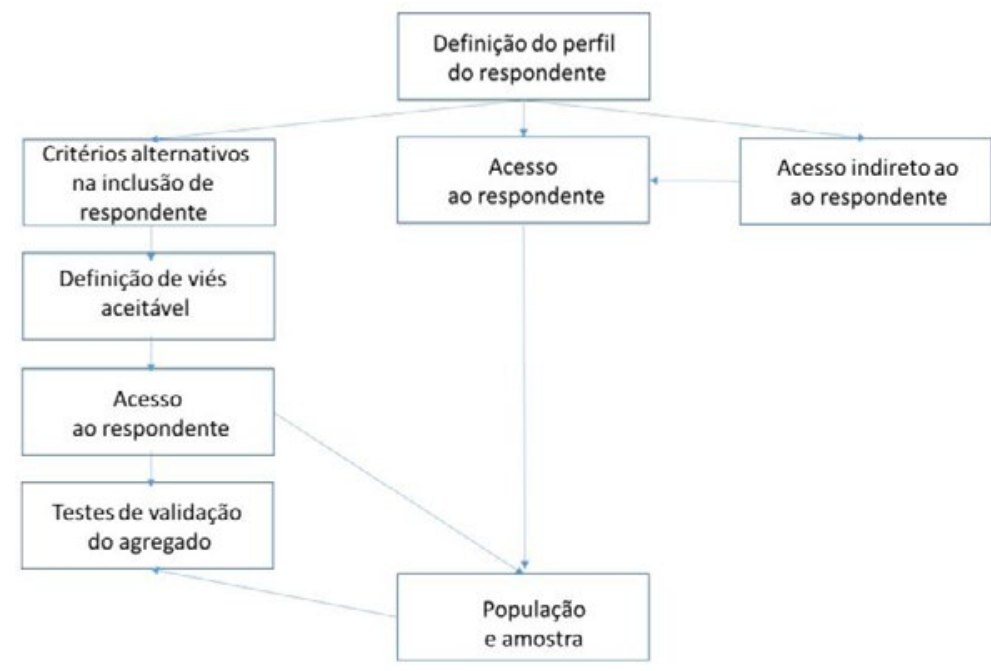

Figura 4. Respondente adequado à pesquisa.

O projeto de pesquisa objeto de estudo definiu o perfil do respondente alvo (Figura 4) com base no nível hierárquico sendo representantes das famílias, presidente, diretores e controllers. Pela pesquisa com a necessidade de tratar de artefatos de controle gerencial e ciclo de vida, delimitou-se que esses executivos seriam bem informados em relação a esses elementos e poderiam fornecer uma informação confiável e ampla sobre essa temática. 
Algumas possibilidades podem ser utilizadas, dependendo da demanda da pesquisa. Determinadas pesquisas demandam respostas dos proprietários, mas muitas vezes esses contatos não estão disponíveis em listas ou em redes sociais e, nesse sentido, dependendo do teor da pergunta, essas questões podem ser direcionadas a executivos que estejam próximos dos proprietários, como os diretores. $\mathrm{O}$ argumento pode ser reforçado com informações adicionais sobre tempo de empresa e tempo na função.

Para muitas empresas levantadas não foi possível identificar um único respondente aderente a esse perfil, enquanto para outras, especialmente aquelas de grande porte, foi possível identificar mais de um respondente. Em alguns casos não foi possível identificar o respondente-alvo, conforme nível hierárquico e, nesse sentido, utilizaram-se critérios alternativos para a inclusão do respondente na amostra (maior nível hierárquico, tempo de empresa, área de atuação) a partir dos quais se delimitou, dentro do grupo de pesquisa, o viés aceitável em relação à resposta. Portanto, o acesso ao respondente com o perfil definido é parâmetro fundamental para a inclusão da empresa na amostra da pesquisa. Esses elementos podem ser observados na Figura 4.

Uma alternativa seria estabelecer um contato com um executivo da empresa que esteja aberto à realização de pesquisas e solicitar que ele faça uma ponte com o proprietário da empresa por LinkedIn ${ }^{\oplus}$, por exemplo. Nesse sentido, em algumas situações, principalmente para as empresas de grande porte, buscouse acesso indireto ao respondente adequado por meio de contatos disponíveis na estrutura amostral.

Ao longo da coleta foram realizadas algumas conversas com respondentes que aceitaram o convite de discutir a abordagem e questionário da pesquisa, com o intuito de gerar aprendizado para o grupo pesquisador (Kemmis et al., 2014) quanto a: (i) motivação para participação da pesquisa; (ii) formato e meio pelo qual o respondente foi contatado; (iii) aderência do respondente ao tema pesquisado; (iv) críticas e sugestões de uma forma geral. Esta etapa foi importante tanto para o teste de validação do agregado, representando uma análise qualitativa do perfil dos respondentes, quanto para as questões mais operacionais como, por exemplo, a sugestão de apresentação da pesquisa por meio de um vídeo curto. Esse último elemento foi pensado como uma estratégia de atrair a atenção dos potenciais respondentes para a pesquisa, podendo impactar assim na população e amostra da pesquisa, pois seria uma forma mais objetiva de comunicar o propósito do estudo a um grupo de profissionais conhecidos pela restrição de tempo.

Questão 3. Quais seriam as abordagens possíveis para aperfeiçoar o gerenciamento da captura de dados relevantes em prazos adequados?

\section{O que a literatura diz e o gap para a área}

Os pesquisadores utilizam vários meios para execução de surveys, como correio, telefone, e-mail, entre outros (Dillman et al., 2014). Nas últimas décadas, houve um aumento significativo de pesquisas realizadas por meio da internet (Fan \& Yan, 2010).

Em comparação aos modelos tradicionais de pesquisas, os levantamentos feitos de forma on-line apresentam diversas vantagens, dentre elas um menor tempo de envio do questionário, menor custo de entrega, mais opções de design e menor tempo para o recebimento das respostas (Smith, 2019; Dillman et al., 2014). No entanto, as pesquisas on-line também enfrentam desafios específicos, como a perda de participantes durante o processo e a baixa taxa de resposta que podem levar a resultados tendenciosos (Couper, 2000; Fricker\&Schonlau, 2002).

$\mathrm{Na}$ literatura, encontra-se uma série de estudos que tentaram revelar os fatores que podem afetar o sucesso das pesquisas survey. Por exemplo, Cycyota e Harrison (2006) apontam que várias técnicas amplamente discutidas na literatura, tais como consentimento prévio, acompanhamento, lembretes, personalização não foram consideradas eficazes para melhorar a taxa de resposta em pesquisas com executivos da alta administração. Dentre os fatores que influenciam as taxas de respostas na área de controle gerencial, Hiebl e Richter (2018) ponderam o estabelecimento de contato prévio com o potencial respondente, uso de amostra não aleatória e foco em gestores de nível hierárquico mais baixo. 
Visto que a taxa de resposta em pesquisas on-line tem sido uma grande preocupação para os pesquisadores, Fan e Yan (2010) e Keusch (2015) sugeriram que a taxa de resposta é influenciada por fatores como a quantidade de tópicos, tempo necessário para responder o questionário, formatação e design do instrumento, facilidade em acessar o link do questionário em diversos navegadores. Apesar de muitos estudos terem sido desenvolvidos para mapear as estratégias para ampliação da taxa de resposta em surveys, esses estudos muitas vezes divergem entre si, pois se trata de uma discussão multidimensional e especialmente contextual. Alguns autores enfatizam os elementos críticos para desenho da pesquisa survey e a importância da customização do método (Smith, 2019; Dillman et al., 2014), e debatem com profundidade de que forma o redesenho das estratégias pode beneficiar os surveys em termos de qualidade das respostas e de taxa de respostas, por exemplo.

\section{Identificação e discussão de contribuição a partir das evidências empíricas}

O contato com os potenciais respondentes da pesquisa ocorreu por meio da plataforma profissional LinkedIn ${ }^{\oplus}$ e por meio de $e$-mail.

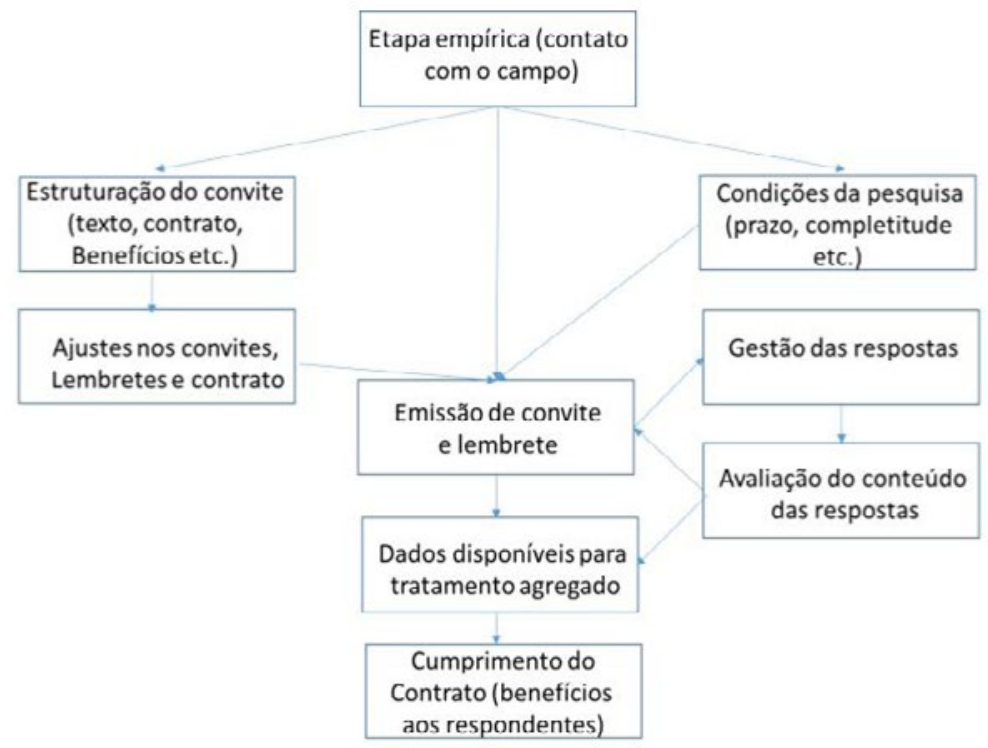

Figura 5. Estratégias para o gerenciamento da coleta de dados.

A estruturação do convite (Figura 5) ocorreu em dois estágios. No contato inicial, os pesquisadores encaminharam um convite padronizado indicando o objetivo da pesquisa e relatando a importância da participação do gestor. Após o aceite do potencial respondente para compor a rede de contatos, os pesquisadores encaminharam uma outra mensagem, um pouco mais detalhada indicando o link para o instrumento de pesquisa. Nessa mensagem foi comunicado um incentivo/benefício para a participação que se tratava da elaboração de um relatório individual e personalizado a cada respondente (organização). Esses e outros atributos da coleta de dados discutidos nesta subseção podem ser observados na Figura 5.

Como comentado, os pesquisadores também convidaram gestores de organizações que já participaram de outras pesquisas ou que faziam parte da rede de contatos do LinkedIn ${ }^{\oplus}$. Observou-se que os gestores que já conheciam os pesquisadores foram mais abertos a participar da pesquisa talvez pela perspectiva de "familiaridade" e confiança. Nesse sentido, pode-se destacar que esses elementos fazem parte da estruturação do convite (incluindo o contrato entre pesquisadores e respondentes). 
Como mencionado anteriormente, os pesquisadores, a partir de entrevistas realizadas com alguns dos respondentes, identificaram oportunidades para aumentar a quantidade e a qualidade de respostas ao questionário. Nesse sentido, foram realizados ajustes nos convites e no contrato. Uma alteração importante foi na forma de comunicação com o potencial respondente que até o momento havia sido realizada apenas em formato de texto. Deste modo, os pesquisadores gravaram vídeos curtos e objetivos, explicando a pesquisa, estratégia que aparentemente gerou um aumento na receptividade da pesquisa. Outro ajuste realizado foi a intensificação do contato por meio do LinkedIn ${ }^{\oplus}$, inclusive para gestores cujos contatos de e-mails estavam disponíveis. Por fim, os pesquisadores também ajustaram o formato do relatório executivo individual encaminhado ao respondente, oferecendo uma linguagem mais direta e em formato gráfico, num prazo máximo de um mês após o recebimento das respostas. Em outras palavras, o respondente recebeu um benefício num horizonte de tempo próximo à sua contribuição.

As condições estabelecidas na pesquisa em termos de prazos e validade das respostas foram sendo monitoradas ao longo de todo o período de coleta de dados. Por exemplo, para ser considerado na pesquisa, o questionário deveria estar preenchido por completo. Nesse caso, quando se identificou que algum respondente não havia finalizado o preenchimento do questionário, esse gestor foi contatado imediatamente acarretando um índice baixo de questionários incompletos.

Quanto à emissão dos convites e lembretes, verificou-se que para esta pesquisa os dias da semana ou horários utilizados para o envio de convites não foram relevantes para a obtenção de respostas. Além dos convites, foram encaminhados lembretes após cerca de três semanas. Acredita-se que os respondentes podem se sentir mais sensibilizados por não terem atendido a oconvite, dando assim uma maior atenção quando recebem o lembrete da pesquisa.

De modo geral, foram feitos três contatos com cada potencial participante, primeiramente o convite da pesquisa, em seguida um lembrete cerca de 20 dias após o envio do convite e, por fim, uma última chamada alguns dias antes de a coleta de dados ser finalizada. Verificou-se que o primeiro lembrete foi efetivo para o aumento de respostas, mas aqueles que não se sensibilizaram com o primeiro lembrete também não foram levados a responder a pesquisa após o chamado final.

Os pesquisadores realizaram o gerenciamento das respostas semanalmente para que pudessem monitorar o recebimento de informações incompletas e agir tempestivamente, avaliar a confiabilidade e dubiedade de respostas em caso de preenchimento por mais de um executivo por empresa,assim como a taxa de adesão para cada estrato de empresas, cluster de acordo com o porte. Essa avaliação permitiu aos pesquisadores gerenciarem o número de respostas por estrato previamente delimitado, procedimento que também balizou a elaboração do relatório executivo individual. Em termos de devolutiva aos respondentes, ao final da coleta de dados deve ser elaborado um relatório executivo com os dados agregados, compartilhado com os respondentes. Cabe destacar que tanto o olhar individualizado como o agregado das respostas trouxeram aos pesquisadores sensibilidade em relação às discussões do projeto de pesquisa. Os aspectos acima mencionados estão alinhados ao contrato firmado com o respondente da pesquisa.

Questão 4. Como aprimorar o relacionamento com as organizações no sentido de obter informações que representem a realidade percebida por eles e pelos pesquisadores?

\section{O que a literatura diz e o gap para a área}

Um tema que tem sido debatido cada vez com maior intensidade no campo da pesquisa científica é o impacto social que ela traz (ou deveria trazer) para a comunidade (Nicolai \&Seidl, 2010). Pesquisadores da área de controle gerencial têm sido sensíveis a essa questão e buscado desenvolver iniciativas/reflexões que permitam à área gerar maior impacto social. Um dos desdobramentos a essa questão é a necessidade de aproximação entre a academia e o ambiente empresarial (Corley\& Gioia, 2011), para que possam ser investigados problemas de pesquisa que espelhem fenômenos relevantes (Shields, 2015; Lindsay, 2018; Merchant, 2012). 
Nesse sentido, um pilar importante para o relacionamento de pesquisadores com gestores de organizações é a percepção de que a pesquisa científica é capaz de trazer contribuição relevante para o contexto profissional. Lindsay (2018) desdobra a relevância em dois aspectos: o primeiro é a reflexão a respeito de práticas e comportamentos e, o segundo, a aplicabilidade prática em termos, por exemplo, de ferramentas de gestão. Esse aspecto é fundamental e os pesquisadores tem que estar atentos ao desenho e à comunicação da pesquisa, especialmente em pesquisas de levantamento, em que normalmente há o distanciamento físico entre pesquisador e respondente.

A percepção quanto à relevância da pesquisa por parte do potencial respondente pode se dar de diversas formas. Primeiro, a familiaridade que o respondente tem em relação ao tema estudado e ao interesse prático de implementação de um artefato de controle gerencial na sua organização, tendo em vista problemas vivenciados no seu dia a dia. Além disso, a percepção do respondente pode ser balizada pelo contato prévio que teve com o pesquisador (em aulas, congressos e outras interações) até mesmo levando em consideração a imagem da instituição de ensino envolvida. Outro instrumento utilizado, especialmente em surveys, são os incentivos para a realização de pesquisas, como doações, relatórios, prêmios, entre outros (Dillman et al., 2014; Smith, 2019).

Pode-se dizer que esses e outros mecanismos fazem parte do contrato entre pesquisadores e potenciais respondentes, abrangendo desde elementos informais (confiança, familiaridade, imagem) a formais (carta-convite, questionário, incentivos). A lógica do contrato tendo como pano de fundo a relevância da pesquisa é de fundamental importância para aprimorar o relacionamento de pesquisadores com as organizações e o desenvolvimento de comunidade de pesquisa. Essa prática possibilita a ampliação da taxa de respostas e esse movimento tende a gerar melhor qualidade das informações obtidas,uma vez que os gestores tendem a estar mais motivados a responder fidedignamente às questões colocadas, pois passam a atribuir maior valor ao processo em si. A consequência dessa postura é proporcionar ao participante a informação, o recebimento de benefício do conhecimento, e esse deveria ser o grande objetivo do processo de pesquisa.

\section{Identificação e discussão de contribuição a partir das evidências empíricas}

Além de conseguir respondentes para a pesquisa realizada em determinado momento, os pesquisadores também se importam com pesquisas futuras e como conseguirão coletar os seus dados de forma oportuna. Obviamente, além da evolução de pesquisas no meio acadêmico, também há a importância da evolução das organizações, afinal a pesquisa em ciências sociais aplicadas é desenvolvida com esse intuito de ligação entre teoria e prática.

Assim, ao contatar os gestores participantes da pesquisa, buscou-se estabelecer um relacionamento entre as empresas e a academia, convidando os gestores a darem suas opiniões, marcando reuniões online para que suas sugestões fossem atendidas, verificando se os relatórios fornecidos, se os convites e se até os temas abordados na pesquisa eram pertinentes. Deste modo, a intenção não era apenas conseguir um determinado número de respondentes, mas sim estabelecer uma relação com as empresas, o que se pode chamar de comunidade de pesquisa.

Essa relação com as empresas foi delineada a partir da lógica de contrato firmado entre pesquisadores e potenciais respondentes desde o primeiro contato estabelecido por meio da plataforma profissional LinkedIn ${ }^{\bullet}$ e por e-mail. A concepção do contrato nesta pesquisa mostra-se alinhada à perspectiva de Borgatti e Molina (2005) em que existe um contrato que descreva claramente o acordo entre as partes, por exemplo a permissão da coleta de dados, tratamento dos dados e o retorno apresentado à empresa. Além disso, os autores sugerem que vários recursos e designs na coleta de dados podem melhorar a experiênciados respondentes. A Figura 6 apresenta os fatores que permeiam a discussão da lógica do contrato. 


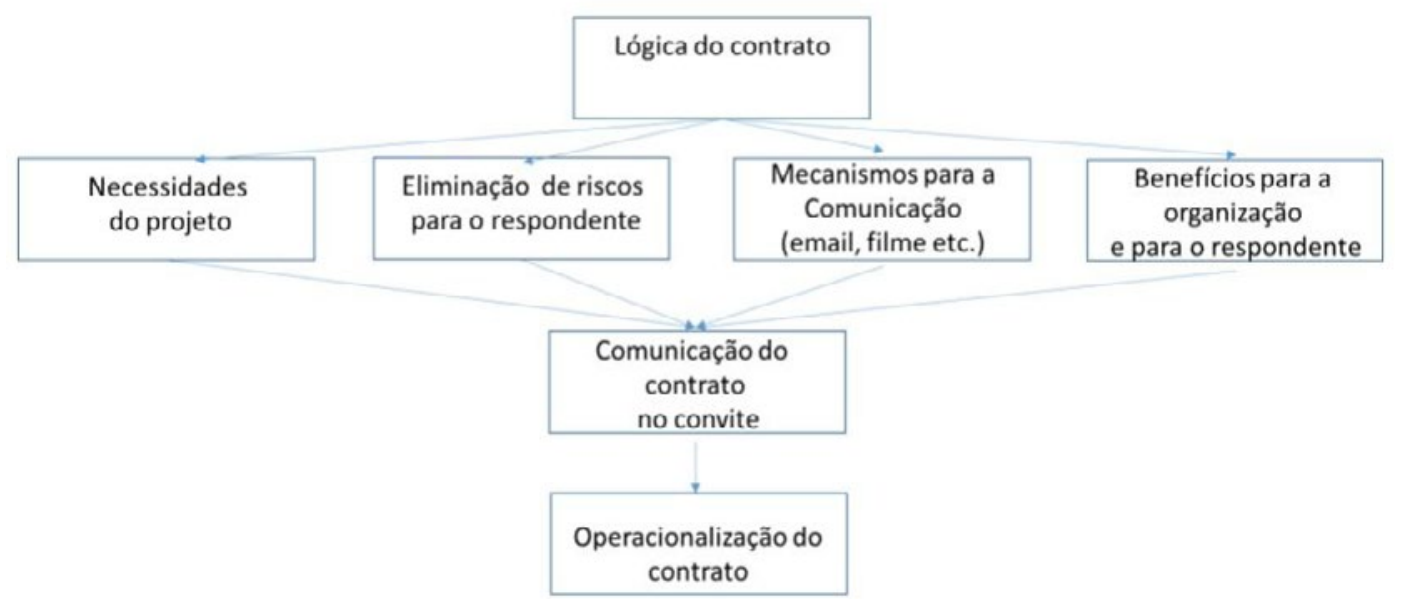

Figura 6. Relacionamento com as organizações.

Por necessidades do projeto, devem ser consideradas as informações necessárias para atender à demanda do construto definido. Um elemento fundamental para a eliminação de riscos ao respondente foi a identificação dos pesquisadores e do grupo de pesquisa por meio do perfil do LinkedIn ${ }^{\otimes}$ e/ou de um e-mail institucional. $\mathrm{O}$ uso do LinkedIn ${ }^{\circledR}$ foi priorizado pelo fato de permitir maior confiança na identificação do pesquisador e do respondente, da inexistência de vírus e spams (como acontece por e-mails) e a possibilidade de desenvolver uma rede de contatos profissionais para interações futuras.

Além disso, os mecanismos de comunicação utilizados buscavam estabelecer a importância da pesquisa e os procedimentos de tratamento de dados como, por exemplo, o sigilo do respondente. Os convites realizados por meio de perfil profissional, bem como os vídeos elaborados para convite e lembrete criaram certa aproximação entre os pesquisadores e os respondentes, fortalecendo os laços de confiança entre as partes.

Cabe destacar também que o contrato estabelecia benefícios para o respondente e para a organização definidos em relação ao compartilhamento de conhecimento gerado na pesquisa. Esse compartilhamento foi realizado por meio de dois relatórios executivos: o primeiro, encaminhado em até um mês após a participação do respondente, o qual continha a análise individualizada da empresa considerando o seu ciclo de vida organizacional, crises e artefatos gerenciais; e o segundo relatório, após a finalização da coleta de dados,em formato agregado de todas as empresas da amostra,permitindo a comparabilidade entre empresas.

Em específico, na pesquisa realizada que serviu como base norteadora deste estudo, o estímulo oferecido na captação de respondentes foi o envio do relatório individual para cada um dos participantes, instigando sobre possíveis oportunidades para o planejamento da organização e realizando essa devolutiva de forma rápida. Ao conversar com alguns dos respondentes, verificou-se que a devolutiva foi pertinente e interessante, contendo gráficos ilustrativos e uma linguagem acessível aos gestores. O envio do relatório agregado partiu da identificação do interesse dos respondentes por essa informação, representando, portanto, uma implementação (Coughlan\& Coghlan, 2002) proveniente da interação com o campo, sendo comum ser enviada após a estruturação da comunicação da pesquisa.

De modo geral, verifica-se que algumas organizações são mais abertas do que outras, essa relação não é algo fácil nem imediato de se criar e talvez não seja possível em apenas uma pesquisa, isto é algo que deve ser construído com o tempo e com cuidado para que não haja o surgimento de vieses, mas sem dúvida é um ponto que acreditamos ser relevante para o avanço da pesquisa survey.

Questão 5. Como aperfeiçoar a confiabilidade das informações obtidas por meio de surveys? 


\section{O que a literatura diz e o gap para a área}

Outro aspecto importante a ser discutido quanto às pesquisas surveys são as práticas de tratamento dos dados durante e após a coleta desses no sentido de verificar a confiabilidade das respostas. Portanto, pretende-se abordar alguns tipos de vieses aos quais a pesquisa survey está sujeita como aqueles decorrentes do uso de técnicas de amostragem não aleatória como o erro de não amostragem (non-samplingerror) e o viés de não resposta (non-response bias) (Van der Stede et al., 2006).

Primeiramente, o erro de não amostragem decorre do uso de técnicas de amostragem não aleatória e pode se desdobrar no erro de não resposta e no erro de resposta, que se referem, respectivamente, a quando alguns gestores convidados não respondem à pesquisa e a quando respondem, mas não de forma adequada (Van der Stede et al., 2006).O erro de não amostragem é comum nas pesquisas da área de controle gerencial, tendo em vista que grande parte dos estudos não adota amostragem aleatória (Van der Stede et al., 2006).

$O$ viés de não resposta (nonresponse bias) trata da medida em que os respondentes diferem dos não respondentes no sentido de generalização dos resultados da pesquisa (Moore \&Tarnai, 2002; Van der Stede et al., 2006). A diferença entre os respondentes e não respondentes pode estar relacionada a alguns fatores, tais como: características do público-alvo (idade, sexo, renda, formação, área de atuação profissional), da organização (porte, setor) e da própria pesquisa (temática, duração, etc.). Tomaksovic-Devey, Leiter e Thompson (1994) ponderam que a autoridade, capacidade e motivação são fatores importantes para a não resposta. A autoridade relaciona-se ao nível hierárquico dos potenciais respondentes; a capacidade ao conhecimento e familiaridade do potencial respondente ao tema e instrumentos de pesquisa; e a motivação abrange o interesse do potencial respondente com a pesquisa. Normalmente o viés de não resposta é abordado nos estudos de controle gerencial por meio das diferenças estatísticas entre os primeiros e últimos respondentes (Van der Stede et al., 2006), tendo em vista que grande parte desses estudos não possui informações da população. Outro ponto discutido por Van der Stede et al. (2006) relaciona-se à não resposta de item ou itens do instrumento de pesquisa (item non-response) tratados como missings, os quais são fonte de vieses e podem gerar problemas de validade e confiabilidade na mensuração dos construtos.

O erro de resposta está presente nas pesquisas que adotam a abordagem survey, pois utilizam dados de resposta do sujeito (self-reported) e, nesse sentido, estão condicionados a diferentes tipos de vieses (Podsakoff et al., 2003), os quais, por exemplo, perpassam por conveniência social e de estados de humor do respondente (Podsakoff et al., 2003). Speklé e Widener (2018) ponderam acerca de dois tipos de vieses, o social desirability bias, que se refere à distorção das respostas visando ao alinhamento com as normas sociais e o halo effect, que reflete a situação em que uma percepção geral influencia um julgamento específico.

Enfim, argumenta-se que, além do desenho em implementação do survey, esses vieses devem ser debatidos após a coleta de dados, no sentido de se verificar em que medida o estudo empírico está sujeito a esses vieses.

\section{Identificação e discussão de contribuição a partir das evidências empíricas}

A pesquisa empírica seguiu os procedimentos de desenho do survey, partindo da definição do perfil do respondente-alvo em termos de nível hierárquico, bem como outros aspectos complementares, por exemplo, a área de atuação e o tempo de empresa. Como já comentado anteriormente, em algumas situações, o respondente-alvo não foi identificado e nesse sentido definiu-se o nível de viés aceitável visando ao acesso ao respondente (conforme pode ser observado na Figura 7). 
Pelo fato de adotar a amostragem por conveniência, esta pesquisa está sujeita tanto ao viés de resposta quanto ao viés de não resposta. O viés de não resposta pode estar presente no estudo e há dificuldade em tratá-lo, uma vez que não é possível delimitar se a amostra tem características semelhantes à população-alvo (devido à ausência de dados sobre a população-alvo), nem mesmo diagnosticar esse viés por meio do teste de primeiros respondentes e últimos respondentes, considerando que os convites foram realizados durante cerca de um ano e que os potenciais respondentes foram agregados à estrutura amostral por meio da identificação dos perfis do LinkedIn ${ }^{\circledast}$.

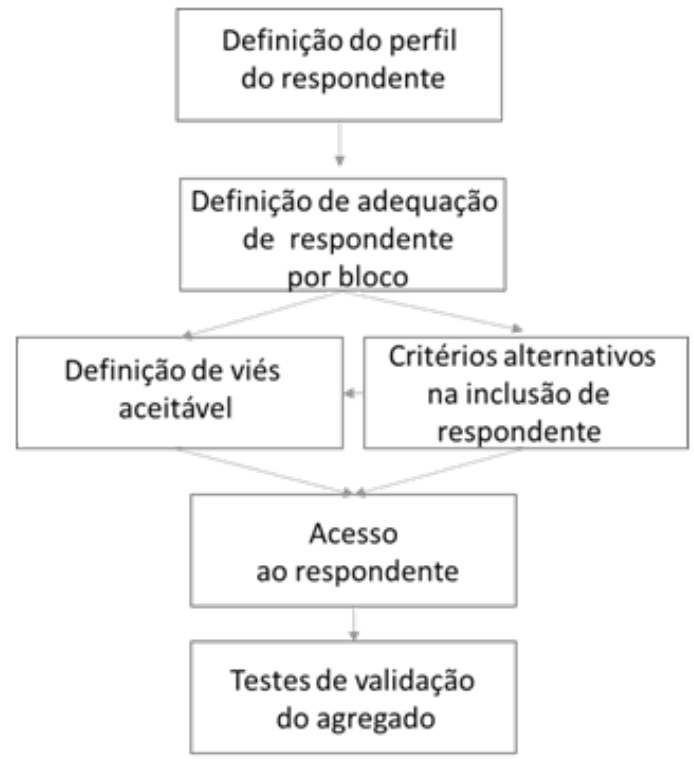

Figura 7. Configuração dos respondentes.

Em se tratando do viés de resposta, os pesquisadores acompanharam o recebimento dos questionários visando rastrear em que medida a resposta era válida e confiável, descartando-se respostas com suspeita de baixa qualidade. Enquanto os atributos autoridade e capacidade do respondente para participar da pesquisa foram tratados por meio do desenho do survey e identificação do potencial respondente, a motivação do respondente foi acompanhada e ajustada ao longo da pesquisa por meio de algumas estratégias. Primeiro, a mudança da carta convite do formato escrito para o vídeo. Segundo, o acompanhamento dos respondentes e o encaminhamento de lembretes, inclusive mencionando a relevância do relatório executivo individual,permitiram reduzir o viés de resposta, bem como o número de missings das respostas e, nesse sentido, construir uma base de dados com poucos respondentes incompletos. Terceiro, foi monitorada a existência de respostas de mais de um respondente por empresa, bem como o tempo de resposta ao questionário, situações que tiveram tratamento específico, por exemplo pela exclusão de alguns dos questionários respondidos.

Conforme apresentado na Figura 8, as questões norteadoras estão alinhadas com os procedimentos de desenvolvimento de surveys e explorados pela literatura, inclusive para a área de controle gerencial (Van der Stede et al., 2006). As questões norteadoras abarcam um ou alguns desses aspectos simultaneamente e foram derivadas da literatura e também do próprio processo de desenvolvimento da pesquisa survey nas empresas familiares brasileiras. 
A partir desse olhar para o processo de condução de uma pesquisa do tipo survey, foram discutidas nesta seção diversas reflexões sobre as dificuldades e as soluções que os pesquisadores implementaram para reduzir os vieses, quando possível, para aumentar a confiabilidade das respostas e aumentar a taxa de respostas, bem como sobre a importância do senso de comunidade de pesquisa. Essas reflexões podem ser percebidas para cada questão norteadora, as quais visam elucidar desafios da viabilização da abordagem de pesquisa survey em face das demandas enfrentadas no processo de investigação,seja pela ausência de dados, pela dificuldade de acesso às organizações e às pessoas, seja pela dificuldade de adaptar os instrumentos de pesquisa ao contexto prático e ao mesmo tempo manter a validade de construto, dentre outros. Conforme destacado por Van der Stedeet al. (2006) e Speklé e Widener (2018), apesar desses desafios, inclusive de aceitação pela comunidade de pesquisa, a abordagem survey é de fundamental importância para o avanço do campo de contabilidade gerencial e da área de ciências sociais aplicadas como um todo.

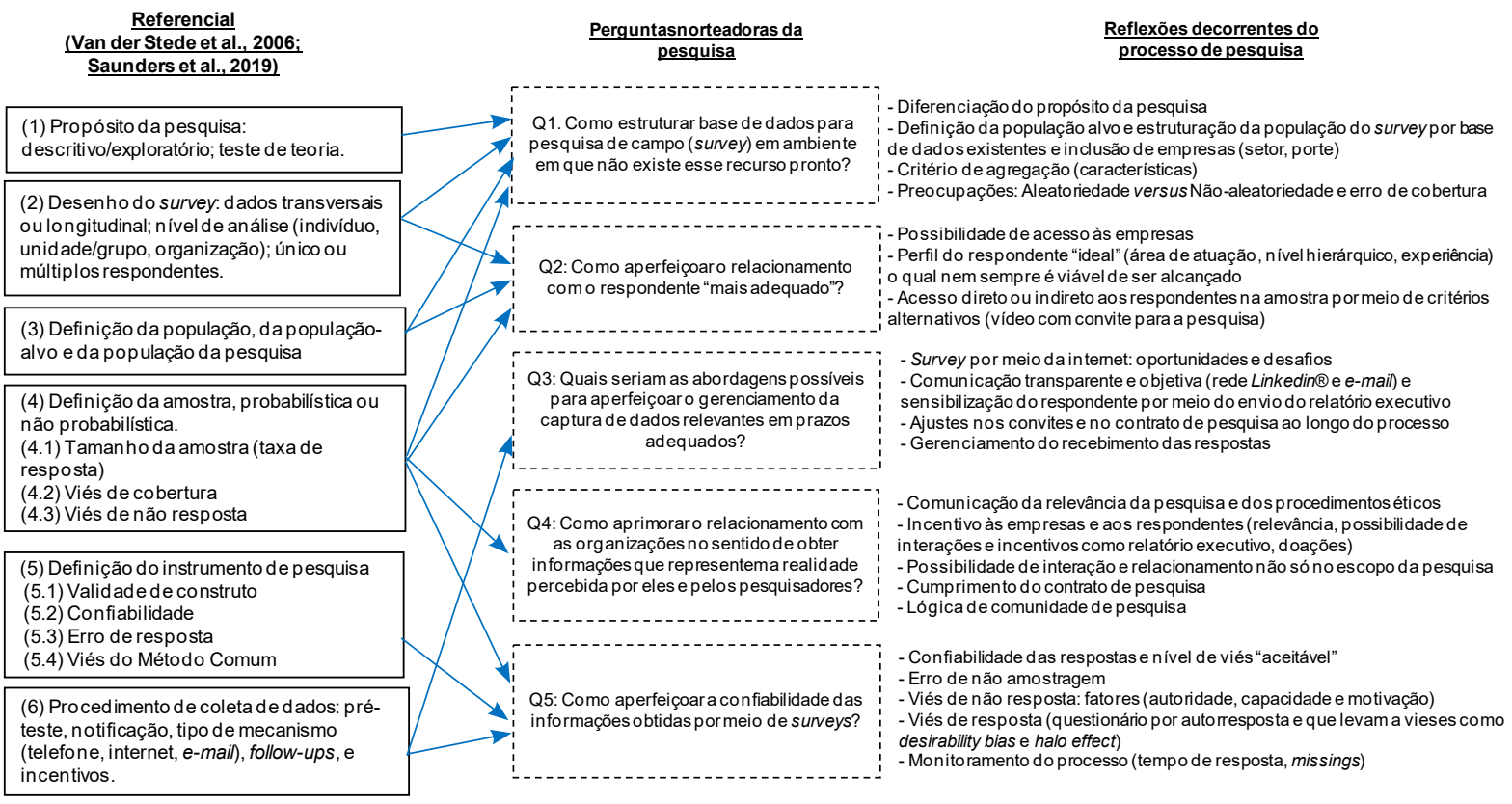

Figura 8. Reflexões sobre o desenvolvimento de surveys.

\section{Considerações Finais}

Este trabalho teve como objetivo discutir as perspectivas metodológicas de levantamentos (surveys), a partir de cinco questões norteadoras que abrangem a estruturação do conjunto de dados, o relacionamento com o respondente, o gerenciamento da coleta de dados, o senso de comunidade de pesquisa e a confiabilidade das informações, perpassando, portanto, perspectivas técnicas e éticas da pesquisa survey.

As propostas estão alinhadas tanto às dificuldades enfrentadas no processo de pesquisa survey como às discussões de estudos anteriores (e.g., Van der Stede et al., 2006; Spékle\&Widener, 2018) e teve como pano de fundo uma pesquisa de campo desenvolvida na área de controle gerencial de empresas familiares. Essas dificuldades muitas vezes não são abordadas com profundidade pelas obras metodológicas, pelo foco pragmático das etapas do processo de coleta de dados. Além disso, quando os pesquisadores estão nesse processo, eles vivenciam uma série de desafios que não foram planejados e que afetam todo o desenho da pesquisa. 
Esse trabalho traz à tona essas questões, a partir do olhar crítico sobre a condução do processo de coleta de dados com questionários, focando ao mesmo tempo na literatura, nas experiências, intervenções e no aprendizado. Este estudo discutiu cada questão norteadora utilizando a perspectiva da pesquisa-ação (action research), tendo, como pano de fundo, o campo para entendimento da realidade, um levantamento realizado com empresas familiares brasileiras de diversos portes tratando da temática de práticas de controle gerencial e ciclo de crescimento organizacional. A partir desse contexto, este estudo explorou dificuldades e soluções na adoção de surveys, a fim de chamar atenção sobre o fato de que o desenho mais adequado de levantamento em muitos casos não é praticável.

Em específico o estudo chama atenção para:(i) a importância da definição da população-alvo e amostra que contemplem a problemática pretendida;(ii) a operacionalização da coleta de dados em si, como atributos do respondente desejável, formato da comunicação e gestão do processo de coleta de dados; e (iii)a importância da lógica de comunidade de pesquisa, que passa pelo estabelecimento e cumprimento do contrato de pesquisa. Deste modo, o olhar interno da "pesquisa da pesquisa" oferece meios para a reflexão e o aprimoramento de surveys e assim permite o avanço de estudos sobre temas relevantes até então pouco explorados, dado o desafio da obtenção de dados.

Como contribuições, espera-se que este artigo propicie reflexões e soluções a outros pesquisadores que utilizam o survey como principal abordagem metodológica de coleta de dados. Particularmente, o survey é um método com grande utilização na área de controle gerencial e, devido a isso, pesquisas recentes têm procurado refletir sobre seu papel, limitações, além de ponderar sobre alternativas para ampliar a aceitação e a viabilidade de surveys nesta área de pesquisa (Speklé\&Widener, 2018; Hiebl\& Richter, 2018). Portanto, este estudo contribui para essa literatura, ao partilhar sobre reflexões no contexto brasileiro, a partir de uma pesquisa realizada com empresas familiares, servindo também como norte para elaboração de pesquisas surveys em outras áreas que enfrentam essas mesmas dificuldades.

\section{Referências}

Bisbe, J., Batista-Foguet, J. M., \&Chenhall, R. (2007). Defining management accounting constructs: a methodological note on the risks of conceptual misspecification. Accounting, Organizations and Society, 32(7-8), pp. 789-820.https://doi.org/10.1016/j.aos.2006.09.010

Borgatti, S. P., \& Molina, J. L. (2005). Toward ethical guidelines for network research in organizations. Social Networks, 27(2), pp. 107-117.https://doi.org/10.1016/j.socnet.2005.01.004

Bressan, A. A., Schiehll, E., Procianoy, J. L., \& Castro, L. R. K. D. (2019). Perspectivas da pesquisa em governança de empresas familiares no Brasil. Revista de Administração Contemporânea,23(6), pp. 696-702.http://dx.doi.org/10.1590/1982-7849rac2019190331

Carneiro, T. C. T., \& Dib, L. A. D. R. (2011). O uso da internet em surveys: oportunidades e desafios. Administração: Ensino e Pesquisa, 12(4), pp. 641-670.https://doi.org/10.13058/raep.2011.v12n4.146

Corley, K., \& Gioia, D. (2011). Building theory about theory building: what constitutes a theoretical contribution? Academy of Management Review, 36(1), pp. 12-32. https://doi.org/10.5465/amr.2009.0486

Coughlan, P., \& Coghlan, D. (2002). Action research for operations management. International Journal of Operations \& Production Management, 22(2), pp. 220-240.https://doi. org/10.1108/01443570210417515

Couper, M. P. (2000). Web surveys: a review of issues and approaches. The Public Opinion Quarterly, 64(4), pp. 464-494.https://doi.org/10.1086/318641

Cycyota, C. S., \& Harrison, D. A. (2006). What (not) to expect when surveying executives: a meta-analysis of top manager response rates and techniques over time. Organizational Research Methods,9(2), pp. 133-160.https://doi.org/10.1177/1094428105280770 
Dillman, D. A., Smyth, J. D., \& Christian, L. M. (2014). Internet, phone, mail, and mixed-mode surveys: the tailored design method. New Jersey:John Wiley \& Sons.

Fan, W., \& Yan, Z. (2010). Factors affecting response rates of the web survey: a systematic review. Computers in Human Behavior, 26(2), pp. 132-139.https://doi.org/10.1016/j.chb.2009.10.015

Freitas, H., Oliveira, M., Saccol, A. Z., \&Moscarola, J. (2000). O método de pesquisa survey. Revista de Administração da Universidade de São Paulo, 35(3), pp. 105-112.

Fricker, R. D., \&Schonlau, M. (2002). Advantages and disadvantages of internet research surveys: evidence from the literature. Field Methods, 14(4), pp. 347-367.https://doi.org/10.1177/152582202237725

Hartmann, F., \&Slapničar, S. (2012). The perceived fairness of performance evaluation: the role of uncertainty. Management Accounting Research, 23(1), pp. 17-33.https://doi.org/10.1016/j.mar.2011.10.004

Hiebl, M. R., \& Richter, J. F. (2018). Response rates in management accounting survey research. Journal of Management Accounting Research, 30(2), pp. 59-79. https://doi.org/10.2308/jmar-52073

Instituto Brasileiro de Geografia e Estatística. IBGE. (2019). Estatísticas do cadastro central de empresas: 2017. IBGE, Coordenação de Cadastro e Classificações. Rio de Janeiro: IBGE.

Kemmis, S., McTaggart, R.,\& Nixon, R. (2014). The action research planner: doing critical participatory action research. Springer: Singapore Heidelberg, New York: Dordrecht London.

Ketokivi, M., \& Choi, T. (2014). Renaissance of case research as a scientific method. Journal of Operations Management, 32(5), pp. 232-240.https://doi.org/10.1016/j.jom.2014.03.004

Keusch, F. (2015). Why do people participate in Web surveys? Applying survey participation theory to internet survey data collection. Management Review Quarterly, 65(3), pp. 183-216.https://doi. org/10.1007/s11301-014-0111-y

Landers, R.N.,\& Behrend, T.S. (2015). An inconvenient truth: arbitrary distinctions between organizational, mechanical Turk, and other convenience samples. Industrial and Organizational Psychology, 8(2), pp. 142-164.https://doi.org/10.1017/iop.2015.13

Lindsay, R. M. (2018). Making progress in management accounting research: towards a practical agenda. Paper presented at the Management Accounting Section Midyear Meeting: American Accounting Association. Recuperado de https://aaahq.org/Meetings/2018/Management-Accounting/Program.

Lodi, M. D. de F., Thiollent, M. J. M., \&Sauerbronn, J. F. R. (2017). Uma discussão acerca do uso da pesquisa-ação em administração e ciências contábeis. Sociedade, Contabilidade e Gestão, 13(1), pp. 57. https://doi.org/10.21446/scg_ufrj.v13i1.14175

Mac Lennan, M. L. F., \&Avrichir, I. (2013). A prática da replicação em pesquisas do tipo survey em Administração de Empresas. Administração: Ensino e Pesquisa, 14(1), pp. 39-61. https://doi. org/10.13058/raep.2013.v14n1.72

Madison, K., Kellermanns, F. W., \&Munyon, T. P. (2017). Coexisting agency and stewardship governance in family firms: an empirical investigation of individual-level and firm-level effects. Family Business Review, 30(4), pp. 347-368.https://doi.org/10.1177/0894486517727422

Merchant, K. A. (2010). Paradigms in accounting research: a view from North America. Management Accounting Research,21(2), pp. 116-120.https://doi.org/10.1016/j.mar.2010.02.004

Merchant, K. A. (2012). Making management accounting research more useful. Pacific Accounting Review,24(3), pp. 334-356.https://doi.org/10.1016/j.mar.2010.02.004

Moore, D. L., \&Tarnai, J. (2002). Evaluating nonresponse error in mail surveys. In: R. M. Groves, D. A.,Dillman, J. L.,Eltinge, \& R. J. A., Little (Eds.).Survey nonresponse. (pp. 197-211). New York, NY: John Wiley \& Sons.

Nicolai, A., \&Seidl, D. (2010). That's relevant! Different forms of practical relevance in management science. Organization Studies, 31(9-10), pp. 1257-1285.https://doi.org/10.1177/0170840610374401 
Podsakoff, P. M., MacKenzie, S. B., Lee, J. Y., \& Podsakoff, N. P. (2003). Common method biases in behavioral research: a critical review of the literature and recommended remedies. Journal of Applied Psychology, 88(5), pp. 879-903.https://doi.org/10.1037/0021-9010.88.5.879

Ribeiro, R. J. (2014). É preciso correr riscos.Revista Contabilidade \& Finanças,25(66), pp. 211-213.http:// dx.doi.org/10.1590/1808-057x201400020

Saunders, M., Lewis, P., \& Thornhill, A. (2019). Research methods. Business Students. (8th edition).UK: Pearson Education Limited.

Shields, M. D. (2015). Established management accounting knowledge. Journal of Management Accounting Research, 27(1), pp. 123-132.https://doi.org/10.2308/jmar-51057

Smith, M. (2019). Research methods in accounting. UK:SAGE Publications Limited.

Speklé, R. F., \& Widener, S. K. (2018). Challenging issues in survey research: discussion and suggestions. Journal of Management Accounting Research,30(2), pp. 3-21.https://doi.org/10.2308/jmar-51860

Speklé, R. F., \& Widener, S. K. (2020). Insights on the use of surveys to study management control systems. Accounting, Organizations and Society, 86 (101184). https://doi.org/10.1016/j.aos.2020.101184

Thiollent, M. (2009). Pesquisa-ação nas organizações. 2a Edição. São Paulo:Atlas.

Tomaskovic-Devey, D., Leiter, J., \&Thompson,S. (1994). Organizational survey non response. Administrative Science Quarterly, 39(3), pp. 439-457.https://doi.org/10.2307/2393298

Tripp, D. (2005). Pesquisa-ação: uma introdução metodológica. Educação e Pesquisa, 31(3), pp. 442-466. https://doi.org/10.1590/S1517-97022005000300009

Van der Stede, W. A., Young, S. M., \& Chen, C. X. (2006). Doing management accounting survey research. Handbooks of Management Accounting Research, 1, pp. 445-478.https://doi.org/10.1016/S17513243(06)01018-2 